\title{
Neurocognitive function impairment after whole brain radiotherapy for brain metastases: actual assessment
}

\author{
Agnes V Tallet ${ }^{1,8^{*}}$, David Azria ${ }^{2,8}$, Fabrice Barlesi ${ }^{3,8}$, Jean-Philippe Spano ${ }^{4,8}$, Antoine F Carpentier ${ }^{5,8}$, \\ Antony Gonçalves ${ }^{6,8}$ and Philippe Metellus ${ }^{7,8}$
}

\begin{abstract}
Whole brain radiation therapy (WBRT) is an effective treatment in brain metastases and, when combined with local treatments such as surgery and stereotactic radiosurgery, gives the best brain control. Nonetheless, WBRT is often omitted after local treatment due to its potential late neurocognitive effects. Publications on radiation-induced neurotoxicity have used different assessment methods, time to assessment, and definition of impairment, thus making it difficult to accurately assess the rate and magnitude of the neurocognitive decline that can be expected. In this context, and to help therapeutic decision making, we have conducted this literature review, with the aim of providing an average incidence, magnitude and time to occurrence of radio-induced neurocognitive decline. We reviewed all English language published articles on neurocognitive effects of WBRT for newly diagnosed brain metastases or with a preventive goal in adult patients, with any methodology (MMSE, battery of neurcognitive tests) with which baseline status was provided. We concluded that neurocognitive decline is predominant at 4 months, strongly dependant on brain metastases control, partially solved at later time, graded 1 on a SOMA-LENT scale (only $8 \%$ of grade 2 and more), insufficiently assessed in long-term survivors, thus justifying all efforts to reduce it through irradiation modulation.
\end{abstract}

Keywords: Neurocognitive impairment, Whole brain radiation therapy, Brain metastases

\section{Introduction}

Neurocognitive effect of whole brain radiation therapy (WBRT) is a crucial problem since fear has led physicians to postpone this effective treatment for patients with oligometastic brain metastases (BM) after local treatment (stereotactic radiosurgery (SRS) or surgery), despite its ability to reduce intracranial failure and neurologic death rates [1-3]. This seems detrimental, especially in patients for whom extra-cranial disease is absent or controlled and the primary tumor radiosensitive. Indeed, in situations of controlled extra-cranial disease, the objective of the treatment of newly diagnosed BM is not only to palliate symptoms, but also and mainly to control BM, and thus

\footnotetext{
* Correspondence: talleta@ipc.unicancer.fr

'Department of Radiation Oncology, Institut Paoli Calmettes, Marseille, France

${ }^{8}$ Groupe de Réflexion sur la Prise en Charge des MétAstases Cérébrales (GRPCMaC, Marseille, France

Full list of author information is available at the end of the article
}

an aggressive approach is required. This is all the more important since, while randomized controlled trials (RCT) evaluating the omission of up-front WBRT did not show a difference in overall survival [1-3], some retrospective trials concerning patients without extra-cranial disease, have shown the opposite $[4,5]$.

Determining the impact of WBRT on neurocognitive function (NCF) would provide support for therapeutic decision making for individual patient, for which we need to elucidate the incidence, time course, intensity, domains of neurocognitive changes following WBRT and their actual impact on patient quality of life (QOL). There is a paucity of data on neurocognitive impairment after WBRT, which has previously been assessed using various different neuropsychological tests, as well as different definitions of neurocognitive impairment. It is noteworthy that $\mathrm{NCF}$ is affected by a number of factors (i.e. BM volume, disease progression [intra and/or extra-

\section{Biomed Central}


cranial progression], chemotherapy, hormonotherapy, surgery, radiation, prior neurologic disease, medications, paraneoplastic effects, etc.) which should be considered when evaluating of the actual neurocognitive effect of treatments such as WBRT.

The objective of this review was to obtain accurate data regarding neurocognitive impairment after WBRT and to objectively include them in decision making at time of BM onset. We carried out a literature review of NCF tools used and their results.

Before the year 2000, most studies concerning the neurocognitive effects of WBRT were retrospective, thus without neurocognitive assessment by validated tests or without reliable baseline evaluation. These studies revealed potential dementia, and/or imaging changes [6-9].

Since 2003, neurocognitive tests have been included in RCT, however, the real impact of WBRT on NCF remains unclear because of the variability in time to assessment, definition of neurocognitive impairment, patient population, radiation doses and especially dose per fraction which is known to be a determinant in late side effects [6].

\section{Methods}

\section{Search strategy}

We carried out a literature review and analysed all English language published articles on neurocognitive effects of WBRT alone (without any concurrent treatment) for newly diagnosed BM or with preventive goal in adult patients, in either a prospective or retrospective setting, whatever the methodology used (MiniMental State Examination (MMSE) [10], battery of neurcognitive tests as described by Meyers and Brown [11]) provided there was a baseline assessment and results were compiled.

We conducted a systematic search using the Medline database up to September 2011. Eligible studies investigated WBRT in one of the study arm. The term "neurocognitive function" combined with the terms "irradiation" and "brain metastases" were used. Relevant articles were reviewed, and the reference lists from these sources were manually searched for additional relevant trials.

Articles were excluded from this literature review if they were individual case reports or review articles. Data extracted from studies included: number of patients accrued and evaluated in the WBRT arm of the study, radiation therapy schedule, disease status when available, neurocognitive tests used, definition of neurocognitive impairment, time of assessment, percentage of patients who experienced a neurocognitive decline. Data extracted from text, tables and figures of the articles were then tabulated.

\section{Results}

We identified 16 articles reporting 12 trials assessing the neurocognitive outcome of patients treated with WBRT alone ( 6 based on the MMSE, 9 on a battery of validated neurocognitive tests, and one using the EORTCRadiation Therapy Oncology Group [RTOG] Late Effects Normal Tissue [LENT]-Subjective, Objective, Management, analytic [SOMA] LS scale). Two of these articles assessed the neurocognitive impairment of WBRT following SRS. One of them used the MMSE as NCF assessment tool [12], the second was the only RCT to have neurocognitive outcome as primary end-point [13].

\section{Assessment on MMSE}

The initial assessments of neurocognitive impairment after WBRT were based on MMSE measurement, both in therapeutic cranial irradiation (TCI) (4 studies), and in prophylactic cranial irradiation (PCI) (1 study).

\section{Neurocognitive outcome after TCI (BM present)}

The impact of fractionation schedule (accelerated hyperfractionation vs. standard accelerated fractionation WBRT) was analysed in a phase III study from the RTOG [14]. The primary end-point was overall survival. Murray et al., and Regine et al., evaluated the MMSE in 182 patients with BM enrolled in the accelerated fractionation arm (30 Gy/10 fractions) $[15,16]$. The authors found that $54.5 \%$ of patients experienced an improvement in their MMSE at any follow-up visit. At two and three months, $29 \%$ and $16 \%$ of patients respectively with pretreatment MMSE 28 to 30 experienced a decline. For patients with pretreatment MMSE $<28$, an improvement in MMSE was observed in $42 \%$ of patients at two months, $33 \%$ at three months, the MMSE was stable in $28 \%$ at two months, $18 \%$ at three months, and declined in $28 \%$ of patients at two months, and 46\% at three months [16] (Table 1). Only the neurocognitive outcome of patients in the accelerated fractionation arm was extracted from these reports, but no difference was found between the two arms. It is noteworthy that a clinically/statistically meaningful drop in MMSE at two and three months was only observed in patients with uncontrolled BM. The authors pointed out the limitations of their secondary analysis due to the poor survival of the patient population, and thus the evaluation of neurocognitive effects of WBRT was restricted to the short term.

The incidence of brain atrophy and decline in MMSE after WBRT [ 40 Gy in 20 fractions with (72\% of patients) or without a $10 \mathrm{~Gy}$ boost] was prospectively described in 92 patients with BM [17]. A decrease in MMSE scores of $\geq 4$ points was observed in $7.4 \%, 11 \%, 20 \%, 12 \%$, $5.9 \%$ of assessable patients at $3,6,9,12$, and 15 months respectively, and no decrease in MMSE was observed thereafter (last assessment: 36 months) (Table 1). This was 
Table 1 Neurocognitive impairment after WBRT as assessed by MMSE

\begin{tabular}{|c|c|c|c|c|c|c|c|c|}
\hline \multirow[t]{3}{*}{ Study } & \multirow[t]{3}{*}{$\mathbf{N}$} & \multirow[t]{3}{*}{ Radiation scheme } & \multirow{3}{*}{$\begin{array}{l}\text { Brain } \\
\text { control }\end{array}$} & \multicolumn{5}{|c|}{ Assessment time } \\
\hline & & & & \multicolumn{5}{|c|}{$\%$ of patients impaired } \\
\hline & & & & 2month & $3 \mathrm{mo}$ & $6 \mathrm{mo}$ & $12 \mathrm{mo}$ & $18 \mathrm{mo}$ \\
\hline Regine et al., 2001 & 182 & $30 \mathrm{~Gy} / 10$ fractions/12 & Yes & 0 & 0 & NR & NR & NR \\
\hline [16] & & days $(\mathrm{TCl})$ & No & 28 & 46 & & & \\
\hline Shibamoto et al., 2008 [17] & 92 & 40 Gy/20 fractions/33 days (TCl) & Yes & NR & 7.4 & 11 & 12 & 0 \\
\hline \multirow[t]{2}{*}{ Corn et al., 2008 [18] } & 92 & $37.5 \mathrm{~Gy} / 15$ fractions/19 days (TCl) & Yes & 18 & 24 & 24 & 28 & 28 \\
\hline & & & No & 23 & 23 & 33 & 38 & 40 \\
\hline \multirow[t]{3}{*}{ Aoyama et al., 2007 [12] } & 41 & 30 Gy/10 fractions/12 days (TCl) & NR & $5^{a}$ & $16^{\mathrm{a}}$ & $16^{a}$ & $28^{a}$ & $40^{a}$ \\
\hline & & & & $2^{b}$ & $10^{b}$ & $14^{\mathrm{b}}$ & $21^{b}$ & $21^{b}$ \\
\hline & & & & $5^{c}$ & $14^{c}$ & $16^{c}$ & $24^{c}$ & $24^{c}$ \\
\hline Sun et al., 2011 [19] & 340 & 30 Gy/15 fractions/19 days (PCI) & NR & NR & 36 & 28 & 23 & NR \\
\hline
\end{tabular}

Only studies from which percentages of patients impaired on NCF could be extracted are reported in this table. WBRT=Whole Brain Radiation Therapy; $\mathrm{TCl}=$ Therapeutic Cranial Irradiation; $\mathrm{PCl}=$ Prophylactic Cranial Irradiation; $\mathrm{NR}=$ not reported; ${ }^{\mathrm{a}}=$ patients who underwent a 3 -point decrease in $\mathrm{MMSE} ;{ }^{\mathrm{b}}=$ patients who underwent a decrease of MMSE $\leq 26{ }^{\circ}{ }^{c}=$ patients who underwent a 3-point decrease in MMSE, excluding those who return to their initial MMSE.

not correlated with brain atrophy. Patients with brain progression were excluded from the evaluation but patients with systemic progressive disease were included, and about half the patients with an MMSE score decrease had systemic progression and a decrease in performance status.

The efficacy of Thalidomide (a putative antiangiogenic agent) concurrently administered with WBRT was assessed in a phase III trial for 156 adult patients with multiple BM [18]. In 92 patients of the WBRT alone arm, the neurocognitive effect of WBRT (37.5 Gy in fractions of 2.5 Gy) was investigated. As shown in Table 1 , $28 \%$ of patients with brain disease control experienced a neurocognitive decline at one year (but the magnitude of this decline was not given), while $38 \%$ of patients with intra-cranial progression showed a drop in MMSE scores from baseline.

Efficacy of WBRT added to SRS at initial treatment of newly diagnosed BM was investigated in a RCT from Aoyama et al.[1] The authors subsequently reported on the NCF deterioration rate of 36 patients (with initial MMSE $\geq 27$ ) enrolled in the WBRT plus SRS arm [12]. The authors assessed the MMSE deterioration every 3 months, and recorded the percentage of patients who experienced a drop in MMSE score at least once, unless they recovered subsequently their initial MMSE, the percentage of patients impaired at a specified time, and the percentage of patients who experienced a decrease of MMSE $\leq 26$ on at least one occasion. The results are presented in Table 1. Interestingly, no statistically significant difference was observed between patients treated with WBRT and SRS and those treated with SRS alone, despite a difference in the time to deterioration, which was longer for the combined treatment group ( $>12$ months for the WBRT + SRS group vs $<8$ months for the SRS group, $p=0.05)$ ). Finally, while a quarter of patients experienced a drop in MMSE at 12 months, this percentage worsened over time, indicating that WBRT is effective at preventing the neurocognitive decline resulting from brain tumor recurrence in the first 2 years, but could be a cause of continuous deterioration of NCF in long-term survivors.

\section{Neurocognitive outcome after $\mathrm{PCl}$ (no BM)}

The effect of prophylactic cranial irradiation (PCI) on NCF and QOL was assessed by Sun et al. [19] in 64 patients with small cell lung cancer (SCLC) without BM and without disease progression after completing definitive therapy. NCF was assessed with MMSE, and Hopkins Verbal Learning Test (HVLT), using the Reliable Change Index (RCI) method [20]. One third of patients experienced a decline in MMSE score 3 months after completion of PCI, while $28 \%$ and $23 \%$ were impaired on the same test at 6 and 12 months respectively (Table 1 ). Moreover, no significant difference in MMSE (except at 3 months) was observed at 1 year when comparing patients submitted to PCI and those without PCI. Conversely, the HVLT was more often impaired at 1 year in the PCI arm, with an average of $30 \%$ of patients impaired at 1 year (compared to $6 \%$ of patients in the observation arm), which is less than the impairment observed at 3 months (Table 2). The authors were unable to separate those patients who did or did not develop BM, due to the small number of events.

\section{Assessment on a battery of validated neurocognitive tests}

A report by Meyers and Brown, to identify the optimal battery of neurocognitive tests to use for patients with central nervous system disease, did not recommended the use of brief mental status evaluation, which only detect significant dementia and have extremely poor sensitivity in 
Table 2 Time, NCF domain impaired, and incidence of NC impairment after WBRT

\begin{tabular}{|c|c|c|c|c|c|c|c|c|c|}
\hline \multirow{3}{*}{ Study } & \multirow[t]{3}{*}{ Radiation scheme } & \multirow[t]{3}{*}{$\mathrm{Nb}$} & \multicolumn{5}{|c|}{ Assessment time } & \multirow{3}{*}{$\begin{array}{l}\text { Domains } \\
\text { impaired }\end{array}$} & \multirow{3}{*}{$\begin{array}{l}\text { Impairment } \\
\text { definition }\end{array}$} \\
\hline & & & \multicolumn{5}{|c|}{$\%$ of patients impaired } & & \\
\hline & & & $1 \mathrm{mo}$ & $2 \mathrm{mo}$ & $3 \mathrm{mo}$ & $5 \mathrm{mo}$ & $12 \mathrm{mo}$ & & \\
\hline \multirow{3}{*}{$\begin{array}{l}\text { Sun et al., } \\
2011 \text { [19] }\end{array}$} & $\mathrm{PCl} 30 \mathrm{~Gy} / 15 \mathrm{fr}$ & 163 & & & & & & ${ }^{\S} \mathrm{HVLT}$ & \\
\hline & & & - & - & $45 \%$ & & $26 \%$ & Recall & \\
\hline & & & & & $44 \%$ & & $32 \%$ & Delayed recall & \\
\hline \multirow{4}{*}{$\begin{array}{l}\text { Meyers et al., } \\
2004 \text { [22] }\end{array}$} & $30 \mathrm{~Gy} / 10 \mathrm{fr} \pm \mathrm{MGd}$ & 401 & - & - & $31 \%$ & - & & ${ }^{*}$ Pegboard & $>2 \mathrm{DS}$ \\
\hline & & & & & $7 \%$ & & & ${ }^{\dagger}$ COWA & $>2$ DS \\
\hline & 30Gy/10fr alone & 208 & & & & & $48 \%$ & ${ }^{\S} \mathrm{HVLT}$ & $\geq 4.5 \mathrm{DS}$ \\
\hline & & & & & & & $48 \%$ & ${ }^{\dagger}$ COWA & $\geq 4.5 \mathrm{DS}$ \\
\hline \multirow[t]{3}{*}{$\begin{array}{l}\text { Chang et al., } \\
2009 \text { [13] }\end{array}$} & $\begin{array}{l}\text { SRS + WBRT } \\
\text { (30 Gy/12 fractions) }\end{array}$ & 28 & & & $64 \%$ & $28 \%$ & & ${ }^{\S} \mathrm{HVLT}$ & $\begin{array}{l}\text { Drop } \geq 5 \\
\text { points }\end{array}$ \\
\hline & & & & & $22 \%$ & & & Delayed recall & \\
\hline & & & & & $11 \%$ & & & $\begin{array}{l}\text { Delayed } \\
\text { recognition }\end{array}$ & \\
\hline \multirow{7}{*}{$\begin{array}{l}\text { Welzel et al., } \\
2008 \text { [27] }\end{array}$} & TCl: 40Gy/20fr & 16 & $9 \%$ & & - & - & - & ${ }^{\S} \mathrm{MCG}$ & $\mathrm{RCl}$ ( $\geq 1$ score $)$ \\
\hline & & & $18 \%$ & $43 \%$ & & & & $\begin{array}{l}\text { Overall cognitive } \\
\text { decline }\end{array}$ & $\begin{array}{l}\mathrm{RCl}(\geq 2 / 12 \\
\text { test scores) }\end{array}$ \\
\hline & & & & $57 \%$ & - & - & - & ${ }^{\S} \mathrm{AVLT}$ & $\mathrm{RCl}$ ( $\geq 1$ score) \\
\hline & PCl: $36 \mathrm{~Gy} / 18 \mathrm{fr}$ & 13 & $23 \%$ & & - & - & - & ${ }^{\S} \mathrm{MCG}$ & $\mathrm{RCl}$ ( $\geq 1$ score) \\
\hline & & & $8 \%$ & $11 \%$ & & & & $\begin{array}{l}\text { Overall cognitive } \\
\text { decline }\end{array}$ & $\begin{array}{l}\mathrm{RCl}(\geq 2 / 12 \\
\text { test scores) }\end{array}$ \\
\hline & & & & $44 \%$ & & & & ${ }^{\S} \mathrm{AVLT}$ & $\mathrm{RCl}$ ( $\geq 1$ score) \\
\hline & & & & - & & & & & \\
\hline $\begin{array}{l}\text { Van Oosterhout et al., } \\
1995 \text { [28] }\end{array}$ & $\begin{array}{l}\mathrm{PCl} \text { (30 Gy } \\
\text { / } 15 \text { fractions) }\end{array}$ & 5 & 0 & & - & 0 & - & none & $>$ ?DS \\
\hline $\begin{array}{l}\text { Komaki et al., } \\
1995 \text { [29] }\end{array}$ & $\begin{array}{l}\mathrm{PCl} \text { (25 Gy } \\
\text { / } 10 \text { fractions) }\end{array}$ & 11 & - & - & - & - & 0 & none & $\geq 1.5 \mathrm{DS}$ \\
\hline \multirow{4}{*}{$\begin{array}{l}\text { Wolfson et al., } \\
2010 \text { [31] }\end{array}$} & $\mathrm{PCl}$ & & & & & & & & \\
\hline & $25 \mathrm{~Gy} / 10 \mathrm{fr}$ & 131 & & & & & $62 \%$ & $\begin{array}{l}{ }^{\S} \mathrm{HVLT},{ }^{+} \mathrm{COWA}, \\
{ }^{\ddagger} \mathrm{TMT}-\mathrm{A} \text { and B }\end{array}$ & $\begin{array}{l}\text { Decrease in at } \\
\text { least one of } \\
\text { the test (from } \\
\text { baseline) (RCl) }\end{array}$ \\
\hline & $36 \mathrm{~Gy} / 18 \mathrm{fr}$ & 67 & & & & & $85 \%$ & & \\
\hline & 36 Gy/twice-daily 24fr & 66 & & & & & $89 \%$ & & \\
\hline
\end{tabular}

Only studies from which percentages of patients impaired on NCF could be extracted are reported in this table. PCI = Prophylactic Cranial Irradiation; MGd = Motexafin Gadolinium; ${ }^{*}$ Pegboard: grooved pegboard test, examining motor speed and dexterity; ${ }^{\dagger}$ COWA: Controlled Oral Word Association, test examining verbal fluency; ${ }^{\S}$ HVLT: Hopkins Verbal Learning Test, examining immediate recall, delayed recall, and recognition; MCG: Medical College of Georgia Complex Figures, examining visual memory and visual construction (copy, immediate recall and delayed recall); AVLT: Auditory Verbal Learning Test, examining verbal memory; ${ }^{\mp}$ TMT-A and B: trailmaking test $A$, examining visual-motor scanning speed, and $B$, examining executive functions.

detecting neurocognitive impairment in brain tumor patients [11].

\section{Neurocognitive outcome after TCI (BM present)}

The effect of Motexafin Gadolinium (MGd) combined with WBRT (30 Gy given in 10 daily fractions) was evaluated in 401 patients with $\mathrm{BM}$ in a multi-institutional phase III study [21-23]. The co-primary end-points were survival and time to neurologic progression. As a secondary endpoint, the authors evaluated the time to neurocognitive progression. The WBRT alone arm included 208 patients, and their neurocognitive outcome was analysed (Table 2). Findings from these reports were: (1) nearly all patients (90.5\%) with multiple metastases (80.1\%) had some 
evidence of neurocognitive impairment at baseline (impairment of one or more neurocognitive tests), $42,4 \%$ having an impairment in four or more tests; (2) this baseline impairment of neurocognitive function was highly correlated to the volume of the indicator lesion at baseline; (3) patients progressed most in pegboard (fine motor) performance at three months; (4) at four months, there was a sharp drop in the mean NCF scores, mainly in memory function, while at 15 months, the mean NCF test scores gradually improved, especially in verbal fluency, executive function and fine motor coordination, but not memory; (5) at 12 months, $48 \%$ of surviving patients treated by WBRT alone (with or without progressive disease) had impaired HVLT and Controlled Oral Word Association Test (COWAT); (6) median time to NCF deterioration for all eight tests was longer in good responders than in poor responders $(p=0.008)$, especially for executive function and fine motor coordination.

Chang et al. described the only RCT with NCF as primary end-point [13]. Patients with 1-3 BM were randomly assigned to SRS alone (30 patients) or SRS plus WBRT (28 patients). The RCI was used to measure meaningful change between baseline and four months for the different tests used; a decline was declared if there was a decline in the total recall score of $\geq 5$ points compared with baseline. The trial was halted by the data monitoring committee according to the early rules on the basis that total recall at 4 months for SRS + WBRT group was inferior to SRS alone group. Of the patients receiving combined treatment, $64 \%$ experienced a decline in total recall tests. Extensive discussions of these results highlighted several shortcomings $[24,25]$, and no definite conclusions could be drawn. In particular, patients in the combined treatment group had a surprisingly, unexplained short median survival which could have had an impact on NCF tests and time of assessment is debatable, since a transient effect on memory following WBRT has already been proved, with a nadir at 4 months [26].

Welzel et al. published a prospective evaluation of neurocognitive effect of WBRT for 44 patients with or without $\mathrm{BM}$, irradiated prophylactically (PCI: 13 patients) or for therapeutic effect (TCI: 16 patients), compared with a control group irradiated on the breast (15 patients) [27]. Patients were described as improved, stable or impaired on NCF using the RCI method. NCF was assessed at baseline, at the "acute phase" (after starting radiotherapy and at its completion), and at the "subacute phase" (at 6-8 weeks after radiotherapy) (Table 2). Approximately one third of the TCI and PCI patients had cognitive impairment on at least two subsets even before treatment. At the end of radiotherapy, almost all verbal memory scores had improved or returned to the baseline level. Declines in visual memory were balanced by improvements. The authors concluded that cognitive dysfunction after WBRT restricted to verbal memory.

\section{Neurocognitive outcome after $\mathrm{PCl}$ (no BM)}

The studies from Van Oosterhout et al. [28], Komaki et al. [29], Grosshans et al. [30], evaluating the neurocognitive outcome of patients subjected to PCI included few patients and the results lacked of precision. Thus, the data from these studies were not detailed, but it was noteworthy that the authors did not observe any consistent neurocognitive impairment after PCI (Table 2).

Impact of different total dose and schedule of PCI on neurologic deterioration was analysed by Wolfson et al. for 264 patients with limited-disease SCLC [31]. Patients who achieved a complete response after chemotherapy and thoracic irradiation, without evidence of brain disease on imaging were randomized to one of the three arms of PCI ( $25 \mathrm{~Gy} / 10$ fractions or $36 \mathrm{~Gy} / 18$ fractions or 36 Gy/twice-daily 24fractions). The NCF assessment (coprimary end-point) was performed at baseline, 6 months and 12 months after randomization. Neurologic deterioration was defined as a decrease of one SEM from baseline in any of the battery of tests, and confirmed using the RCI. More than $60 \%$ of patients receiving 25 Gy and $80-90 \%$ of those having 36 Gy PCI had documented neurotoxicity at one year (as defined above) (Table 2). The second co-primary end-point was QOL measured by the EORTC QLQ-C30 and brain module (BN20). There was no impact of this neurologic deterioration on QOL measurements at 12 months. Moreover, the neurocognitive outcome of the patients included in this series was assessed using the LS scale [32]. LS memory decline at 3 years was more frequent with grade 1 deficit (decreased short term, difficulty with learning), as was observed in $44 \%$ of patients, than grade $\geq 2$ deficit observed in $8 \%$ of patients without intra-cranial progressive disease. The authors concluded that mild deterioration of some items, such as memory, intellectual deficit and cognitive functions possibly related to PCI, should be balanced by considering the beneficial effects of PCI on survival and incidence of BM.

\section{Discussion}

Radio-induced neurocognitive impairment evolves in a biphasic pattern: a subacute transient decline with a peak at four months, and a late delayed irreversible impairment of NCF several months or years after completion of WBRT [26,33-35]. The objective of this review was therefore to identify the incidence of these disorders in the two phases in order to provide support for therapeutic decision making. The first phase is of importance for patients with worse prognoses (due to progression of extra-cranial disease), whereas for long-term survivors, 
the late delayed impairment will strongly influence the therapeutic decision.

Of course, the NCF decline is not exclusively due to WBRT, and as mentioned above, several factors may make it worse. Moreover, pre-treatment cognitive status (highly correlated to the volume of the disease) has significant effects on neurocognitive outcome, as reported by Meyers et al. [22].

Neurocognitive decline in patients without visualizable brain disease. This literature review shows that for patients with brain disease control, the risk of neurocognitive impairment as assessed by MMSE is low (0 to $24 \%$ of patients impaired at 3 months, 12 to $28 \%$ at one year). A lower incidence of a drop in MMSE was observed by Regine et al. [16], and Shibamoto et al. [17] compared to that observed by Corn et al. [18], which may simply reflect the difference in defining the decline in MMSE, which was a decrease in MMSE scores of $\geq 4$ points and a decrease of $\geq 3$ points respectively for the two first publications, and only one point or more for the last. Most studies assessing NCF in the setting of PCI (with lower total doses and dose per fraction than therapeutic cranial irradiation) showed very low incidence of neurocognitive impairment at one year. This had previously been observed in a study investigating the benefit of PCI for non small cell lung cancer, in which neurocognitive decline was assessed using a battery of neurocognitive tests (without baseline evaluation) [36]. The authors found not significant difference for long term survivors in patients with or without PCI. Similar results were reported by Arriagada et al. in a trial assessing the efficiency of PCI for SCLC [37].

Neurocognitive decline in patients with BM present. Based on Table 1, NCF as assessed by MMSE score is impaired after WBRT in the year following the completion of WBRT, but appears strongly related to uncontrolled brain metastases. Later assessments were not available, except in the study from Aoyama et al., which appeared to have shown that neurocognitive decline occurred continuously over time. For this reason, the authors subsequently attempted to isolate prognostic factors for brain recurrence in patients with expected long survival, with the objective to withhold WBRT [38,39]. They found that patients who had solitary BM in the absence of extracranial metastases were at lower risk of brain tumor recurrence compared with patients with multiple BMs or extracranial disease, and proposed to postpone WBRT in those cases, given that the brain tumor recurrence risk was $31 \%$ at 6 and 12 months in patients at lower risk without "up-front" WBRT, allowing $69 \%$ of patients to avoid unnecessary treatment.

When patients were assessed through a battery of neurocognitive tests, almost half of patients were affected by a decline, namely 31 to $57 \%$ at 3 months, and 48 to $85 \%$ at one year, depending on the definition of impairment (Table 2).

WBRT-induced neurocognitive toxicity is to be balanced against the neurocognitive toxicity that may cause brain disease recurrence. Some publications describe a correlation between brain failure and neurocognitive decline and subsequently altered QOL [12,21-23,40,41]. These prospective clinical trials demonstrate a potential benefit of successful WBRT (i.e., achieving intracranial disease control) on NCF-preservation [16,22]. The authors highlighted the fact that patients who demonstrated good radiologic response to WBRT had improved executive function and fine motor coordination, but not memory, suggesting that WBRT might specifically impair hippocampus-related functions, leading to the concept of hippocampus avoidance during WBRT. One RCT (from Virginia Commonwealth University) with this objective was undertaken but unfortunately was closed for lack of accrual (only 8 patients enrolled). Two phase II trial (RTOG: http://clinicaltrials. gov/ct2/show/ NCT01227954, NCT01414738) and one phase III trial (France: http://www.sante.gouv.fr/IMG/ pdf/resultats_PHRC_2011_cancer-2.pdf) are ongoing.

\section{Conclusion}

Neurocognitive impairment is of concern in the setting of WBRT delivered for BM. WBRT after local treatment (surgery or SRS) allows the best brain disease control to be obtained to date. Thus, it is necessary to minimize its late side effects, and thereby patient enrollment in clinical trials for WBRT needs to be expanded so that multiple methods for avoiding and mitigating acute and late toxicities may be developed. Local treatment alone for oligometastatic brain disease is an option since postponing WBRT has not shown significant impact on overall survival. The results of this review will enable physicians to inform patients about benefits and risks of these two treatment options.

\section{Abbreviations \\ WBRT: Whole brain radiation therapy; BM: Brain metastases; SRS: Stereotactic radiosurgery; RCT: Randomized controlled trials; NCF: Neurocognitive function; QOL: Quality of life; MMSE: Mini-Mental State Examination; EORTC: European Organisation for Research and Treatment of Cancer; RTOG: Radiation Therapy Oncology Group; LENT: Late Effects Normal Tissue; SOMA: Subjective, Objective, Management, analytic; LS scale: SOMA-LENT scale; PCl: Prophylactic cranial irradiation; SCLC: Small cell lung cancer; HVLT: Hopkins Verbal Learning Test; RCI: Reliable change index; MGd: Motexafin Gadolinium; COWAT: Controlled Oral Word Association Test; TCI: Therapeutic cranial irradiation; SEM: Standard error of mean; EORTC QLQ- C30: EORTC quality of life questionnaire.}

\section{Competing interest}

AT received honoraria from Roche, DA received honoraria from Roche, Sanofi and Novartis, FB received honoraria from Roche, AC is consultant for Roche, AG received honoraria and funding supports from Roche, GSK and Astra Zeneca, PM received honoraria from Roche, JPS received honoraria or funding supports from: Roche, GSK, Merck, and Astra Zeneca, We are not actually sure that this could constitute any conflict of interest in connection with this manuscript. 


\section{Author details}

'Department of Radiation Oncology, Institut Paoli Calmettes, Marseille, France. ${ }^{2}$ Department of Radiation Oncology and INSERM U896, CRLC Val d'Aurelle, Montpellier, France. ${ }^{3}$ Multidisciplinary Oncology and Therapeutic Innovations Department \& Centre Investigation Clinique, Aix Marseille University -Assistance Publique Hôpitaux de Marseille, Marseille, France. ${ }^{4}$ Department of Medical Oncology, GH Pitié-Salpêtrière, Université Paris 6, Paris, France. ${ }^{5}$ Department of Neurology, Hopital Avicenne, Assistance Publique des Hopitaux de Paris, Bobigny, France. ${ }^{6}$ Department of Medical Oncology, Institut Paoli Calmettes, Centre de Recherche en Cancérologie de Marseille, UMR1068 INSERM, Aix-Marseille University, Marseille, France. ${ }^{7}$ Department of Neurosurgery, Hopital La Timone, Assistance PubliqueHôpitaux de Marseille and INSERM UMR 911, Marseille, France. ${ }^{8}$ Groupe de Réflexion sur la Prise en Charge des MétAstases Cérébrales (GRPCMaC, Marseille, France.

\section{Authors' contributions}

AT and PM performed the literature search and wrote the manuscript. JPS, $A F C$ and $A G$ performed critical revision. $A D$ and $F B$ participated in the conception as well as the preparation of the manuscript; All authors read and approved the final manuscript.

Received: 17 February 2012 Accepted: 28 May 2012

Published: 28 May 2012

\section{References}

1. Aoyama $\mathrm{H}$, Shirato $\mathrm{H}$, Tago M, Nakagawa $\mathrm{K}$, Toyoda $T$, Hatano $\mathrm{K}$, et al: Stereotactic radiosurgery plus whole-brain radiation therapy vs stereotactic radiosurgery alone for treatment of brain metastases: a randomized controlled trial. JAMA 2006, 295(21):2483-91.

2. Patchell R, Tibbs PA, Regine WF, Dempsey RJ, Mohiuddin M, Kryscio RJ, et al: Postoperative radiotherapy in the treatment of single metastases to the brain: a randomized trial. JAMA 1998, 280(17):1485-89.

3. Kocher M, Soffietti R, Abacioglu U, Villà S, Fauchon F, Baumert BG, et al: Adjuvant whole-brain radiotherapy versus observation after radiosurgery or surgical resection of one to three cerebral metastases: results of the EORTC 2295226001 study. J Clin Oncol 2011, 29(2):134-41.

4. Pirzkall A, Debus J, Lohr F, Fuss M, Rhein B, Engenhart-Cabillic R, Wannenmacher M: Radiosurgery alone or in combination with whole-brain radiotherapy for brain metastases. J Clin Oncol 1998, 16:3563-69.

5. Smalley SR, Laws ER Jr, O'Fallon JR, Shaw EG, Schray MF: Resection for solitary brain metastasis: Role of adjuvant radiation and prognostic variables in 229 patients. J Neurosurg 1992, 77:531-40.

6. DeAngelis LM, Delattre JY, Posner JB: Radiation-induced dementia in patients cured of brain metastases. Neurology 1989, 39:789-96.

7. Asai A, Matsutani M, Kohno T, Nakamura O, Tanaka H, Fujimaki T, et al: Subacute brain atrophy after radiation therapy for malignant brain tumor. Cancer 1989 63:1962-74.

8. Frytak S, Shaw JN, O'Neill BP, Lee RE, Eagan RT, Shaw EG, et al: Leukoencephalopathy in small cell lung cancer patients receiving prophylactic cranial irradiation. Am J Clin Oncol 1989, 12:27-33.

9. Laukkanen $\mathrm{E}$, Klonoff H, Allan B, Graeb D, Murray N: The role of prophylactic brain irradiation in limited stage small cell lung cancer: clinical, neuropsychologic, and CT sequelae. Int J Radiat Oncol Biol Phys 1988, 14: 1109-17.

10. Folstein MF, Folstein SE, McHugh PR: "Mini-mental state": A practical method for grading the cognitive state of patients for the clinician. J Psychiatr Res 1975, 12:189-98.

11. Meyers CA, Brown PD: Role and relevance of neurocognitive assessment in clinical trials of patients with CNS tumors. J Clin Oncol 2006, 24:1305-09.

12. Aoyama H, Tago M, Kato N, Toyoda T, Kenjyo M, Hirota S, et al: Neurocognitive function of patients with brain metastasis who received either whole brain radiotherapy plus stereotactic radiosurgery or radiosurgery alone. Int J Radiat Oncol Biol Phys 2007, 68(5):1388-95.

13. Chang EL, Wefel JS, Hess KR, Allen PK, Lang FF, Kornguth DG, et al Neurocognition in patients with brain metastases treated with radiosurgery or radiosurgery plus whole-brain irradiation: a randomised controlled trial. Lancet Oncol 2009, 10(11):1037-44.

14. Murray K, Scott C, Greenberg HM, Emami B, Seider M, Vora NL, et al: A randomized phase III study of accelerated hyperfractionation versus standard in patients with unresected brain metastases: A report of the Radiation Therapy Oncology Group (RTOG) 9104. Int J Radiat Oncol Biol Phys 1997, 39:571-74

15. Murray KJ, Scott C, Zachariah B, Michalski JF, Demas W, Vora NL, et a Importance of the mini-mental status examination in the treatment of patients with brain metastases: a report from the Radiation therapy Oncology Group protocol 91-04. Int J Radiat Oncol Biol Phys 2000, 48(1):59-64.

16. Regine WF, Scott C, Murray KJ, Curran W: Neurocognitive outcome in brain metastases patients treated with accelerated-fractionation vs. accelerated-hyperfractionated radiotherapy: an analysis from Radiation therapy Oncology Group study 91-04. Int J Radiat Oncol Biol Phys 2001, 51 (3): $: 11-17$.

17. Shibamoto Y, Baba F, Oda K, Hayashi S, Kokubo M, Ishihara S, et at: Incidence of brain atrophy and decline in Mini-Mental State Examination score after whole-brain radiotherapy in patients with brain metastases: a prospective study. Int J Radiat Oncol Biol Phys 2008, 72(4):1168-73.

18. Corn BW, Moughan J, Knisely JP, Fox SW, Chakravarti A, Yung WK, et al: Prospective evaluation of quality of life and neurocognitive effects in patients with multiple brain metastases receiving whole-brain radiotherapy with or without thalidomide on Radiation Therapy Oncology Group (RTOG) trial 0118. Int J Radiat Oncol Biol Phys 2008, 71 (1):71-8

19. Sun A, Bae K, Gore EM, Movsas B, Wong SJ, Meyers CA, et al: Phase III trial of prophylactic cranial irradiation compared with observation in patients with locally advanced non-small-cell lung cancer: neurocognitive and quality-of-life analysis. J Clin Oncol 2011, 29(3):279-86.

20. Jacobson NS, Truax P: Clinical significance: A statistical approach to defining meaningful change in psychotherapy research. J Consult Clin Psychol 1991, 59:12-19.

21. Mehta MP, Rodrigus $P$, Terhaard CH, Rao A, Suh J, Souhami $L$, et al: Survival and neurologic outcomes in a randomized trial of motexafin gadolinium and whole-brain radiation therapy in brain metastases. J Clin Oncol 2003, 21(13):2529-36.

22. Meyers CA, Smith JA, Bezjak A, Mehta MP, Liebmann J, Illidge T, et al: Neurocognitive function and progression in patients with brain metastases treated with whole-brain radiation and motexafin gadolinium: results of a randomized phase III trial. J Clin Oncol 2004, 22 (1):157-65

23. Li J, Bentzen SM, Renschler M, Mehta MP: Regression after whole-brain radiation therapy for brain metastases correlates with survival improved neurocognitive function. J Clin Oncol 2007, 25(10):1260-66.

24. Mahmood U, Kwok K, Regine WF, Patchell RA: Whole-brain irradiation for patients with brain metastases: still the standard of care. Lancet Oncol 2010, 11(3):221-2.

25. Weiss SE, Kelly PJ: Neurocognitive function after WBRT plus SRS or SRS alone. Lancet Oncol 2010, 11(3):220-1.

26. Armstrong C, Ruffer J, Corn B, DeVries K, Mollman J: Biphasic patterns of memory deficits following moderate-dose partial brain irradiation: neuropsychologic outcomes and proposed mechanisms. J Clin Oncol 1995, 13:2263-71.

27. Welzel G, Fleckenstein K, Schaefer J, Hermann B, Kraus-Tiefenbacher U, Mai SK, Wenz F: Memory function before and after whole brain radiotherapy in patients with and without brain metastases. Int J Radiat Oncol Biol Phys 2008, 72(5):1311-8

28. van Oosterhout AG, Boon PJ, Houx PJ, ten Velde GP, Twijnstra A: Follow-up of cognitive functioning in patients with small cell lung cancer. Int $J$ Radiat Oncol Biol Phys 1995, 31(4):911-4.

29. Komaki R, Meyers CA, Shin DM, Garden AS, Byrne K, Nickens JA, Cox JD: Evaluation of cognitive function in patients with limited small cell lung cancer prior to and shortly following prophylactic cranial irradiation. Int J Radiat Oncol Biol Phys 1995, 33(1):179-82.

30. Grosshans DR, Meyers CA, Allen PK, Davenport SD, Komaki R: Neurocognitive function in patients with small cell lung cancer. Cancer 2008, 112(3):589-95.

31. Wolfson AH, Bae K, Komaki R, Meyers C, Movsas B, Le Pechoux C et al: Primary Analysis of a Phase II Randomized Trial Radiation Therapy Oncology Group (RTOG) 0212: Impact of Different Total Doses and Schedules of Prophylactic Cranial Irradiation on Chronic Neurotoxicity and Quality of Life for Patients with Limited-Disease Small-Cell Lung Cancer. Int J Radiat Oncol Biol Phys 2011, 81(1):77-84 
32. Le Péchoux C, Laplanche A, Faivre-Finn C, Ciuleanu T, Wanders R, Lerouge $\mathrm{D}$, et al: Prophylactic Cranial Irradiation (PCI) Collaborative Group. Clinical neurological outcome and quality of life among patients with limited small-cell cancer treated with two different doses of prophylactic cranial irradiation in the intergroup phase III trial (PCI99-01, EORTC 2200308004, RTOG 0212 and IFCT 99-01). Ann Oncol 2011, 22(5):1154-63.

33. Sheline G, Wara WM, Smith V: Therapeutic irradiation and brain injury. Int J Radiat Oncol Biol Phys 1980, 6:1215-28.

34. Butler JM, Rapp SR, Shaw EG: Managing the cognitive effects of brain tumor radiation therapy. Curr Treat Options Oncol 2006, 7(6):517-23.

35. DeAngelis LM, Posner JB: In Side effects of radiation therapy, Neurologic complications of cancer. 2nd edition. Edited by DeAngelis LM, Posner JB. New York: Oxford University Press; 2009:551-555.

36. Pöttgen C, Eberhardt W, Grannass A, Korfee S, Stüben G, Teschler H, et al: Prophylactic cranial irradiation in operable stage IIIA non small-cell lung cancer treated with neoadjuvant chemoradiotherapy: results from a German multicenter randomized trial. J Clin Oncol 2007, 25(31):4987-92.

37. Arriagada R, Le Chevalier T, Borie F, Rivière A, Chomy P, Monnet I, et al: Prophylactic cranial irradiation for patients with small-cell lung cancer in complete remission. J Natl Cancer Inst 1995, 87(3):183-90.

38. Aoyama H: Radiation therapy for brain metastases in breast cancer patients. Breast Cancer 2011, 18(4):244-51.

39. Abe E, Aoyama H: The Role of Whole Brain Radiation Therapy for the Management of Brain Metastases in the Era of Stereotactic Radiosurgery. Curr Oncol Rep 2012, 14(1):79-84.

40. Regine WF, Huhn JL, Patchell RA, St Clair WH, Strottmann J, Meigooni A, et al: Risk of symptomatic brain tumor recurrence and neurologic deficit after radiosurgery alone in patients with newly diagnosed brain metastases: Results and implications. Int J Radiat Oncol Biol Phys 2002, 52:333-8.

41. Rosenman J, Choi NC: Improved quality of life of patients with small-cell carcinoma of the lung by elective irradiation of the brain. Int J Radiat Oncol Biol Phys 1982, 8(6):1041-3.

doi:10.1186/1748-717X-7-77

Cite this article as: Tallet et al:: Neurocognitive function impairment after whole brain radiotherapy for brain metastases: actual assessment. Radiation Oncology 2012 7:77.

\section{Submit your next manuscript to BioMed Central and take full advantage of:}

- Convenient online submission

- Thorough peer review

- No space constraints or color figure charges

- Immediate publication on acceptance

- Inclusion in PubMed, CAS, Scopus and Google Scholar

- Research which is freely available for redistribution 